\title{
Tectonic implications on the 2018 Hualien Earthquake
}

\author{
Strong Wen ${ }^{1, *}$, Yi-Ying Wen ${ }^{1}$, Kuo-En Ching ${ }^{2}$, Yu-Lien Yeh $^{1}$, and Yuan-Hsi Lee ${ }^{1}$ \\ ${ }^{1}$ Department of Earth and Environmental Sciences, National Chung Cheng University, Chiayi County, Taiwan \\ ${ }^{2}$ Department of Geomatics, National Cheng Kung University, Tainan City, Taiwan
}

\author{
Article history: \\ Received 19 August 2018 \\ Revised 15 January 2019 \\ Accepted 28 January 2019 \\ Keywords: \\ 2018 Hualien earthquake, 3D veloc- \\ ity structure, Focal mechanism, Fluid \\ migration \\ Citation: \\ Wen, S., Y.-Y. Wen, K.-E. Ching, \\ Y.-L. Yeh, and Y.-H. Lee, 2019: \\ Tectonic implications on the 2018 \\ Hualien Earthquake. Terr. Atmos. \\ Ocean. Sci., 30,389-398, doi: $10.3319 /$ \\ TAO.2019.01.28.01
}

\begin{abstract}
The 2018 Hualien earthquake occurred at the junction of the deformed continental crust of Eurasian plate and the Heping sea basin, where a northeast trending seismic belt exists. In this study, a 3D seismic tomographic inversion is used to investigate the seismogenic structures of the 2018 Hualien earthquake sequence. An earthquake relocation procedure is performed and the focal mechanisms are analyzed to study the faulting behavior. Our results indicate that the source region of the 2018 Hualien earthquake consists of complex high-angle eastward and westward dipping reverse faulting. We also observe that most earthquakes that have occurred in the area exhibit considerable variation in $\mathrm{Vp} / \mathrm{Vs}$ ratios. Fluid migration may have played an essential role in causing the $\mathrm{Vp} / \mathrm{Vs}$ ratio variation. We suggest that the mainshock of the 2018 Hualien earthquake may be associated with a west-dipping fault, which is a blind fault tending toward the Heping sea basin and possibly belonging to the Central Range fault system.
\end{abstract}

\section{INTRODUCTION}

As Taiwan is located in the circum-Pacific seismic belt and is frequently affected by earthquakes, a large amount of seismic data is available, and we can take advantage of this wealth of data to gain a better understanding of the tectonic structures in eastern Taiwan. In this region, most of the earthquakes have occurred at shallow depths, so knowledge of the high potential of earthquake hazards in this region is a critical issue. Recently, several disastrous earthquakes have struck eastern Taiwan, for example, a moderate earthquake $\left(\mathrm{M}_{\mathrm{L}}=6.4\right.$; depth $\left.=15 \mathrm{~km}\right)$ occurred in Ruisui, Hulien County on 31 October 2013, and seven months later, close to the location of this event, another moderate earthquake $\left(\mathrm{M}_{\mathrm{L}}=5.9\right.$, depth $\left.=18 \mathrm{~km}\right)$ occurred in Fenglin, Hualien County, on 21 May 2014. In early February 2018, a seismic swarm comprising hundreds of small earthquakes occurred off-shore of Heping area, where the collision boundary of eastern Taiwan is located (Fig. 1, yellow dots). The largest magnitude among this swarm is up to $\mathrm{M}_{\mathrm{L}}$ 5.7. On 6 February 2018 , another moderate earthquake $\left(\mathrm{M}_{\mathrm{L}}=6.2\right.$; depth

\footnotetext{
* Corresponding author

E-mail: strong@eq.ccu.edu.tw
}

$=6 \mathrm{~km}$ ) occurred off-shore of Heping area and caused severe damage, including buildings collapse, bridge destruction, surface rupture and causing casualties in Hualien City, which was previously affected by the 1951 Hulien-Taitung earthquake (Shyu et al. 2007). This devastating earthquake raised important questions, including whether the event was triggered by the abovementioned seismic swarm, whether the faulting behavior of this earthquake involved multiple ruptures, and whether the event triggered known fault systems. Therefore, the study of seismogenic structures in this area is a very important issue.

Seismic swarms are generally thought to be caused by fluids invading the seismogenic zone and hence their behaviors pattern differs significantly from that of an earthquake sequence. Hence, the main goal of this study is to investigate the seismogenic structure of the 2018 Hualien earthquake and its tectonic implications beneath the northern part of the Longitudinal Valley in east Taiwan. Several regional-scale seismic tomographic studies in Taiwan have been reported, such as Liaw and Yeh (1983), Yeh et al. (1989), Kao and Rau (1999) for northeastern Taiwan and Cheng et al. (2002) for eastern Taiwan. These studies suggest that, in the basement 
of the Longitudinal Valley and Coastal Ranges, there exists a narrow stripe-like high-velocity zone that belongs to the Luzon arc and may extend toward $24^{\circ} \mathrm{N}$. Although several 3-D models of $\mathrm{Vp}$ or $\mathrm{Vp} / \mathrm{Vs}$ ratio have been proposed based on seismic travel-time data in the Taiwan area (Kim et al. 2005; Wu et al. 2007; Kuo-Chen et al. 2012; Huang et al. 2014), they only provide large-scale velocity structure mappings, and their overall resolution is insufficient to describe velocity variations within a small area. Therefore, we intend to invert a high resolution mapping of 3-D velocity structures beneath the northern Longitudinal Valley, eastern Taiwan, which would provide better insights into the seismogenic structure of the 2018 Hualien earthquake.

\section{BACKGROUND GEOLOGICAL SETTING}

The terrain distribution in eastern Taiwan can be divided into three geological units: from west to east, the Central Mountain Range (CMR), the Longitudinal Valley (LV), and the Coastal Ranges (CR). The CMR is located in the extreme west of our study area; it has a terrain height of 1000 - $2000 \mathrm{~m}$ and is composed of metamorphic rock. The LV is located between the CMR and the CR and is a flat valley approximately $150 \mathrm{~km}$ long. The LV is segmented mainly by different types of faulting behaviors as well as the accumulation of alluvial deposits from the CMR. The ongoing vigorous orogenic processes in Taiwan result in active tectonic processes and frequent earthquakes. The $\mathrm{CR}$ is located above the Philippine Sea plate; it belongs to the Luzon arc and fills up with fore-arc sediments. In the northern segment of the LV, most earthquakes occur on plate boundaries with reverse faulting mechanisms.

The LV is a plate suture zone. As the Philippine Sea Plate moves at a rate of $8 \mathrm{~cm} \mathrm{yr}^{-1}$ toward the Eurasian plate in the northwest direction (Yu et al. 1997), violent crustal deformation occurs in the LV, forming the Longitudinal Valley Fault (LVF) system (Shyu et al. 2006a; Thomas et al. 2014). The main LVF is a thrust fault and dips eastward (see Fig. 1). The exposed fault traces are roughly along the foothills of the western part of the CR, which can be divided into several segments from the Hualien to Taitung areas (Shyu et al. 2006a; Thomas et al. 2014). Two major active faults in the Hualien area are the Linding Fault (LDF) (Lin et al. 2009) and the Milun Fault (MLF), which may be considered the northernmost

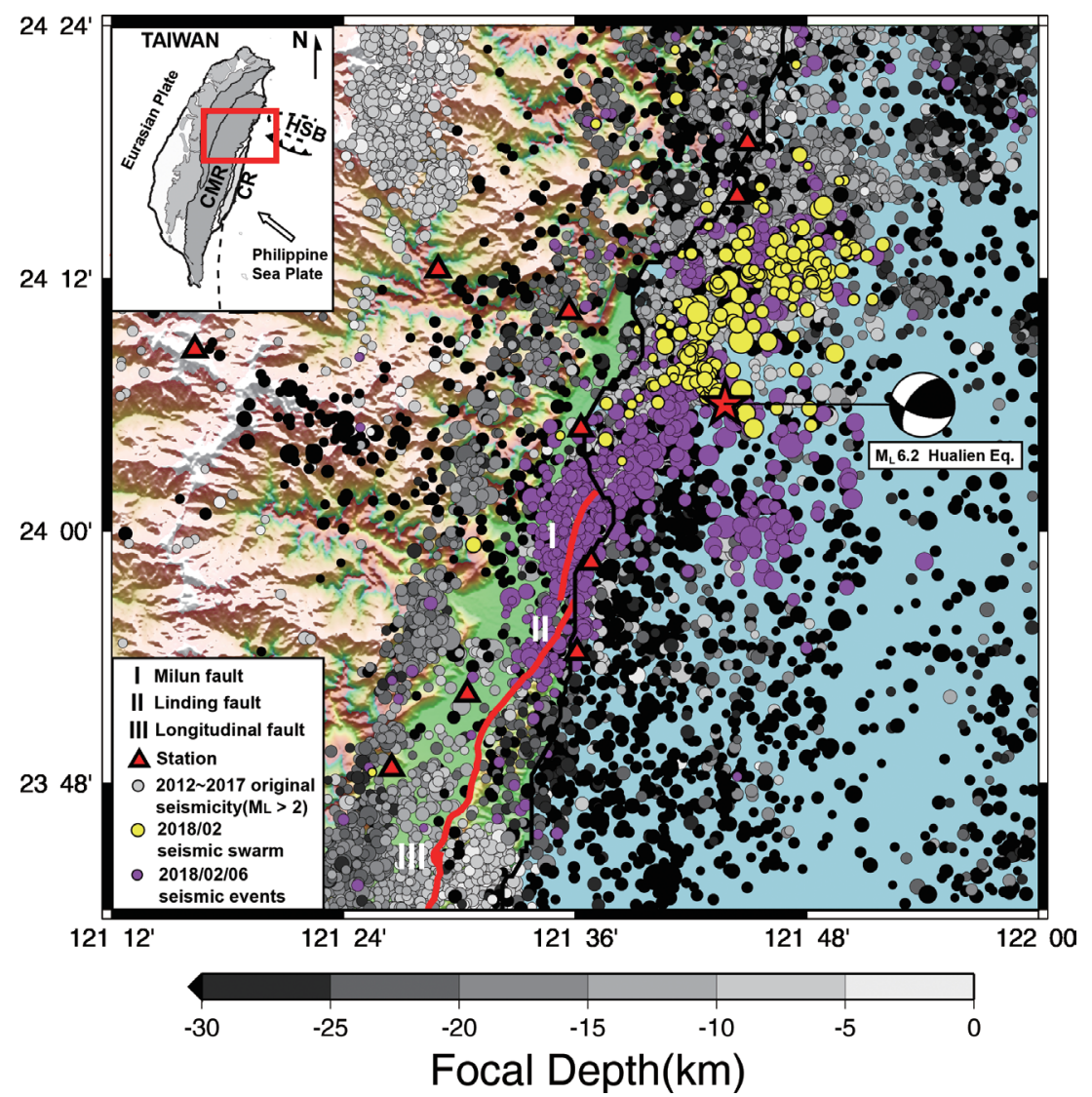

Fig. 1. Locations of the faults (denoted by numbers I - III) and the stations of the CWBSN and BATS in our research area (denoted by red triangles). The gray circles $\left(\mathrm{M}_{\mathrm{L}}>2\right)$ indicate seismicity data from the period 2012 - 2017. The yellow circles represent the seismic swarm before the occurrence of the 2018 Hualien earthquake, while the purple circles represent the aftershocks of the 2018 Hualien earthquake. The focal mechanism represents the mainshock of the 2018 Hualien earthquake. The dashed-line circle indicates the location of the Heping sea basin (HSB) in the upper left inset. 
extension of the LVF (see Fig. 1). Shyu et al. (2007) pointed out that the LVF is segmented by different slip behaviors. Another major fault in the LV is the Central Range Fault (CRF) (Shyu et al. 2006b). However, the fault trace of the CRF is not obvious and its position is still controversial. In addition, the CRF is considered to represent the boundary between the CMR and the LV. The geometry of the boundary between the CMR and the LV from previous studies is quite complex and slightly different from south to north; this boundary does not always correspond to the foothills of the eastern edge of the CMR. Geological and geophysical surveys also indicated that the CRF may be a blind fault, especially in the northern part of the LV (Shyu et al. 2006b).

The northern part of the LV experiences high seismicity (Kuo-Chen et al. 2004; Chuang et al. 2014; Thomas et al. 2014) with most of the seismic activities being caused by the LVF. A few seismic activities have occurred in the CRF, such as the 2013 Ruisui earthquake (Chuang et al. 2014; Wen et al. 2016) and the 2014 Fenglin earthquake, whose epicenters were on the eastern edge of the CMR. The distribution of the aftershocks shows that the seismogenic fault is a west-dipping fault. Furthermore, the aftershocks are only distributed to a depth up to about $5 \mathrm{~km}$, which implies that the CRF is still in a locked state above the depth of $5 \mathrm{~km}$ (Shyu et al. 2006b).

\section{3D LOCAL TOMOGRAPHY MODEL}

In this study, we used travel time data of $\mathrm{P}$ and $\mathrm{S}$ waves with a local magnitude greater than 2 recorded by the Central Weather Bureau Seismic Network (CWBSN) and the Broadband Array in Taiwan for Seismology (BATS) for the period 2012 - 2017 (see Table 1 for the station list). A damped least-square inversion method (Thurber 1983; Eberhart-Phillips and Michael 1998) was used to determine the $\mathrm{Vp}$ structures and the $\mathrm{Vp} / \mathrm{Vs}$ ratios in the crust and the upper mantle of the region. The study area extends from 23.7 $-24.4^{\circ} \mathrm{N}$ in latitude and $120.9-122^{\circ} \mathrm{E}$ in longitude. Many seismic events occurred in the region of interest (Fig. 1). In order to improve the resolution of tomographic inversion and to obtain a uniform ray distribution in all directions, we chose events with epicenter location errors of less than $5 \mathrm{~km}$ and those with more than six readings for the $\mathrm{P}$ and $\mathrm{S}$ waves. Under these criteria, we were able to select 10309 events with $105705 \mathrm{P}$-wave and $94279 \mathrm{~S}$-wave arrival times.

We chose a priori 1-D P-velocity model modified from Chen et al. (1994) and Wu et al. (2007), following the approach of Kissling et al. (1994), to obtain an initial reference model (the minimum 1-D model), which can roughly represents the main features of a known velocity structure. We further parameterized the model by using horizontal layers of constant velocities, which capture the main features of the velocity structure (Table 2). We parameterized the 3D structure by forming even 2-D grids through a trial-and-error pro- cess (see Fig. 2a). The velocity inversion was damped carefully by calculating a range of damping values to determine the tradeoff between the data residuals and model variances (see the Supplement, Fig. S1). Thus, the final damping values chosen for inverting $\mathrm{Vp}$ and $\mathrm{Vp} / \mathrm{Vs}$ ratios were 20 and 10 , respectively. We used a horizontal grid size of $6 \mathrm{~km} \times 6 \mathrm{~km}$ in this study. It is worth mentioning that, in our inversion, the effect of station elevation on the $3 \mathrm{D}$ tomographic inversion was also taken into account so that the seismic rays can be traced exactly to the true station position.

\subsection{Model Examination}

We examined our final inversion results for various model parameters by using checkerboard test and derivative weight sum test (Toomey and Foulger 1989), and present the outcomes in this section.

Table 1. Station list.

\begin{tabular}{ccc}
\hline Station code & Longitude $\left({ }^{\circ} \mathbf{E}\right)$ & Latitude $\left({ }^{\circ} \mathbf{N}\right)$ \\
\hline HWA & $121^{\circ} 36.81^{\prime}$ & $23^{\circ} 58.51^{\prime}$ \\
SML & $120^{\circ} 54.49^{\prime}$ & $23^{\circ} 52.89^{\prime}$ \\
ESL & $121^{\circ} 26.49^{\prime}$ & $23^{\circ} 48.71^{\prime}$ \\
WHF & $121^{\circ} 16.35^{\prime}$, & $24^{\circ} 8.61^{\prime}$ \\
TWD & $121^{\circ} 36.29^{\prime}$ & $24^{\circ} 4.86^{\prime}$ \\
TWT & $121^{\circ} 11.04^{\prime}$ & $24^{\circ} 15.09^{\prime}$ \\
EHP & $121^{\circ} 44.94^{\prime}$ & $24^{\circ} 18.45^{\prime}$ \\
DPDB & $120^{\circ} 55.58^{\prime}$ & $24^{\circ} 2.00^{\prime}$ \\
ENLB & $121^{\circ} 36.10^{\prime}$ & $23^{\circ} 54.22^{\prime}$ \\
NACB & $121^{\circ} 35.68^{\prime}$ & $24^{\circ} 10.43^{\prime}$ \\
TDCB & $121^{\circ} 9.50^{\prime}$ & $24^{\circ} 15.19^{\prime}$ \\
SSLB & $120^{\circ} 57.24^{\prime}$ & $23^{\circ} 47.25^{\prime}$ \\
CHGB & $121^{\circ} 10.44^{\prime}$ & $24^{\circ} 3.61^{\prime}$ \\
VWDT & $121^{\circ} 8.47^{\prime}$ & $23^{\circ} 45.22^{\prime}$ \\
OWD & $121^{\circ} 10.55^{\prime}$ & $23^{\circ} 57.27^{\prime}$ \\
ETLH & $121^{\circ} 28.91^{\prime}$ & $24^{\circ} 12.41^{\prime}$ \\
\hline
\end{tabular}

Table 2. P-wave velocity and Vp/Vs ratio of 1D initial model.

\begin{tabular}{ccc}
\hline Depth $(\mathbf{k m})$ & $\mathbf{V p}\left(\mathbf{k m ~ s}^{\mathbf{- 1}}\right)$ & $\mathbf{V p} / \mathbf{V s}$ \\
\hline $0-2$ & 4.08 & 1.78 \\
$2-5$ & 5.07 & 1.78 \\
$5-10$ & 5.11 & 1.78 \\
$10-15$ & 5.76 & 1.78 \\
$15-25$ & 6.21 & 1.78 \\
$25-35$ & 7.15 & 1.78 \\
$35-50$ & 8.05 & 1.76 \\
$50-75$ & 8.05 & 1.80 \\
\hline
\end{tabular}



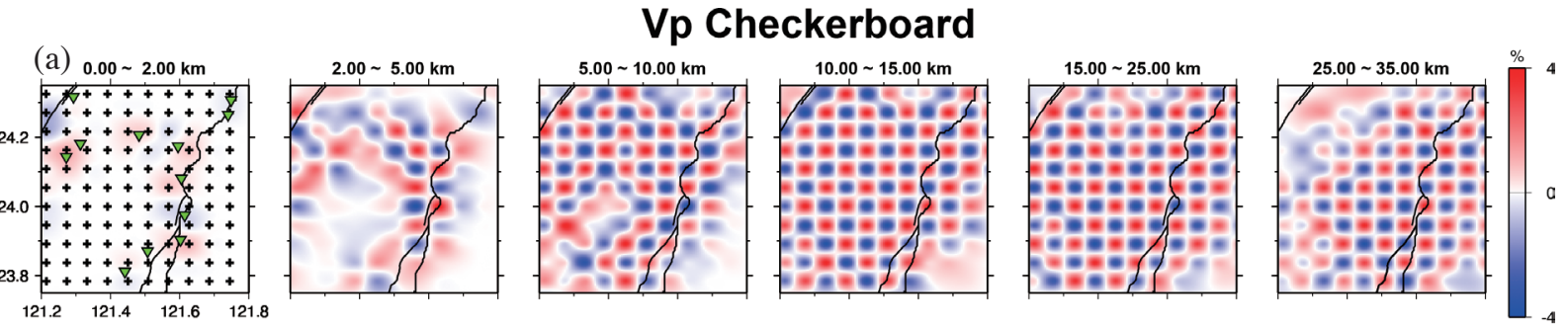

(b) $0.00 \sim 2.00 \mathrm{~km}$
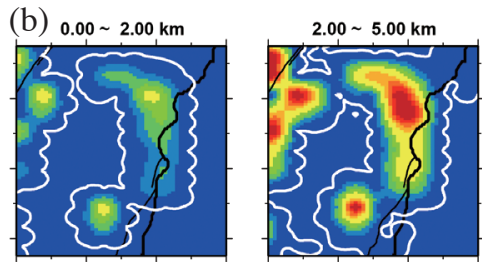

\section{DWS}
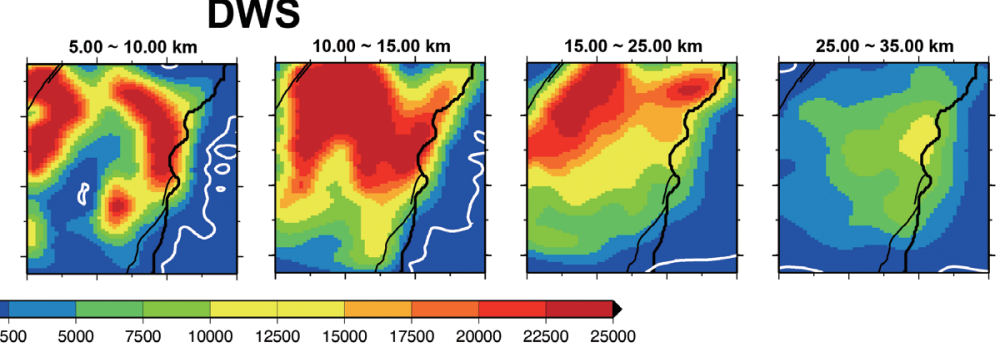

Vp Perturbation
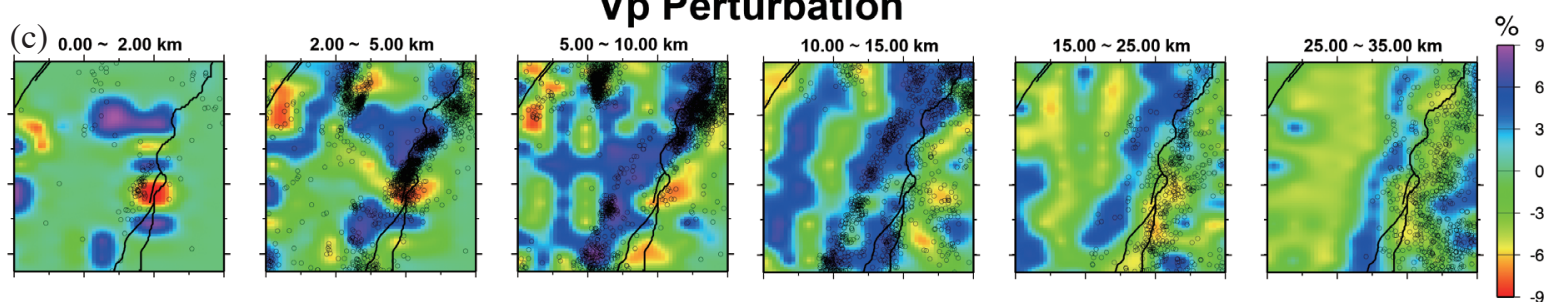

Fig. 2. Checkerboard test (top panel), derivative weighted sum (middle panel), and 3-D tomographic Vp structure (bottom panel) at six depth ranges $(0-2,2-5,5-10,10-15,15-25,25-35 \mathrm{~km})$. An even grid node distribution in the study area which is showed in layer $0-2 \mathrm{~km}$.

\subsubsection{Checkerboard Test}

We used a checkerboard test to illustrate the resolution of the 3D tomographic model. First, the $1 \mathrm{D}$ velocity model (Table 2) was perturbed by $\pm 4 \%$ as the initial velocity model and the theoretical traveling time data was calculated. Then, the synthetic data was inverted to obtain the checkerboard structure. Because only a few stations were located in the oceanic area, the density of the rays across the oceanic area was relatively low resulting in a low spatial resolution of the tomographic inversion for the oceanic area. As the distributions of the seismic events on land were clustered, high-resolution inversion results were obtained at the LVF and in a $\sim 15 \mathrm{~km}$-wide band along the sides of the LVF (see Figs. 2a and 3a). However, the resolution at depth $0-2$ and $25-35 \mathrm{~km}$ was relatively low. The low resolution for depths of $0-2 \mathrm{~km}$ may be because the incident angles were almost perpendicular to the surface, which lowered the lateral resolutions of the velocity. For depths greater than $25 \mathrm{~km}$, the majority of the seismic events occurred in oceanic region and only a few were selected under our criteria, leading to a low resolution. For the deeper part of the crust or in the upper mantle, low seismicity also resulted in a low ray density, thus producing a poor resolution. Nevertheless, the overall resolution in each layer was good. The high- resolution area indicates that the seismic rays crossed most of the crustal region and can be reliable used to determine the geological structures beneath the northern LVF area more precisely.

\subsubsection{Derivative Weighted Sum}

In addition to the checkerboard test, in order to ensure the confidence level of our model, we used the derivative weighted sum (DWS) was first proposed by Toomey and Foulger (1989) as a parameter to estimate the seismic ray density. Small DWS values indicate poorly sampled nodes (Toomey and Foulger 1989). In Figs. 2b and 3b, the areas enclosed by white curves are those with a ray density greater than 50. At the depths $5-25 \mathrm{~km}$, the DWS is high, indicating a high confidence level for this area. This phenomenon is obvious in the vicinity of the MLF and LDF and especially in the northern part of the LV.

\section{RELOCATIONS AND FAULT PLANE SOLUTIONS}

After tomographic inversion, an earthquake relocation procedure was performed using the velocity structure derived from our inversion results. In Fig. 4, the spatial distribution of relocated events is denoted by circles, with their size scaled according to the earthquake magnitudes and their color representing the focal depth, scaled by a grey scale 

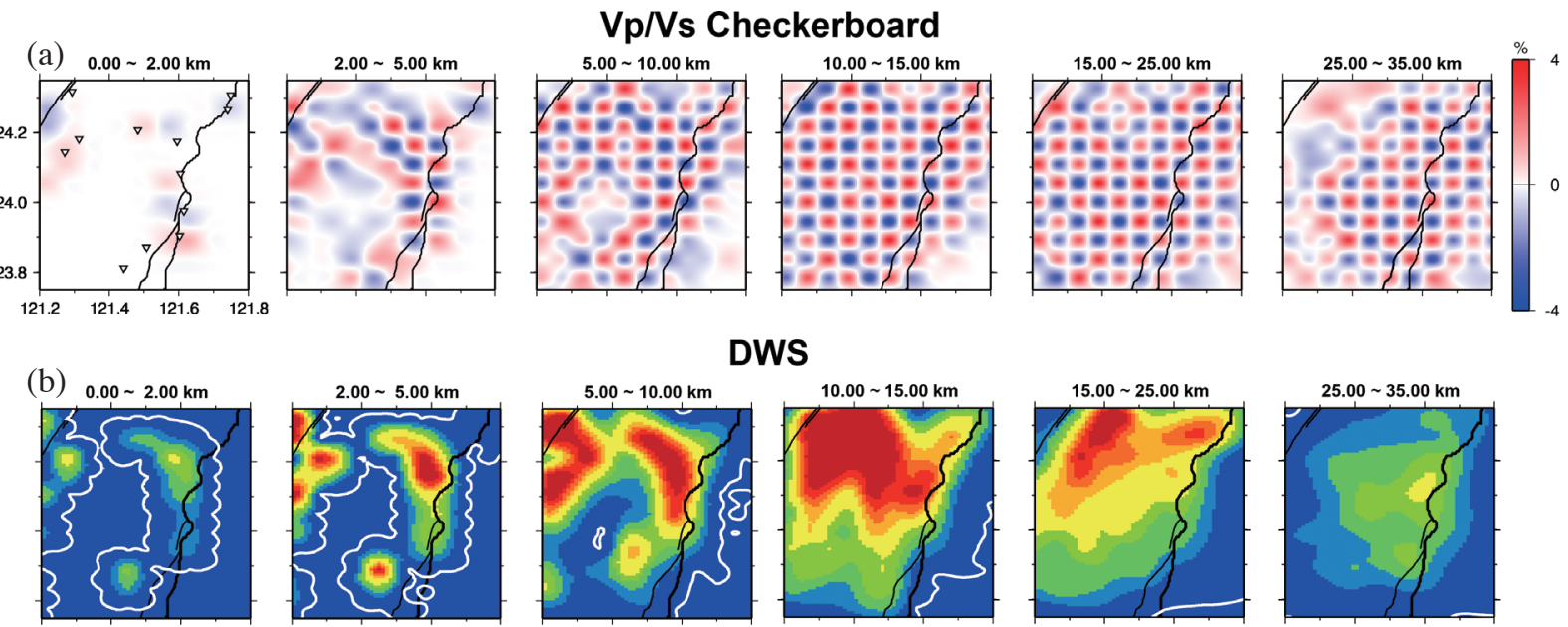

\section{DWS}
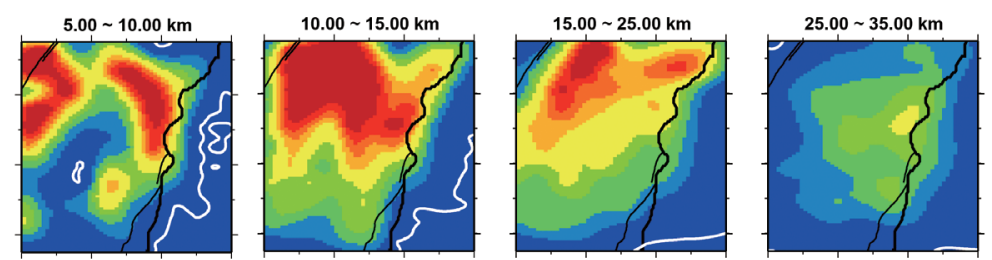

0

(c) $0.00 \sim 2.00 \mathrm{~km}$
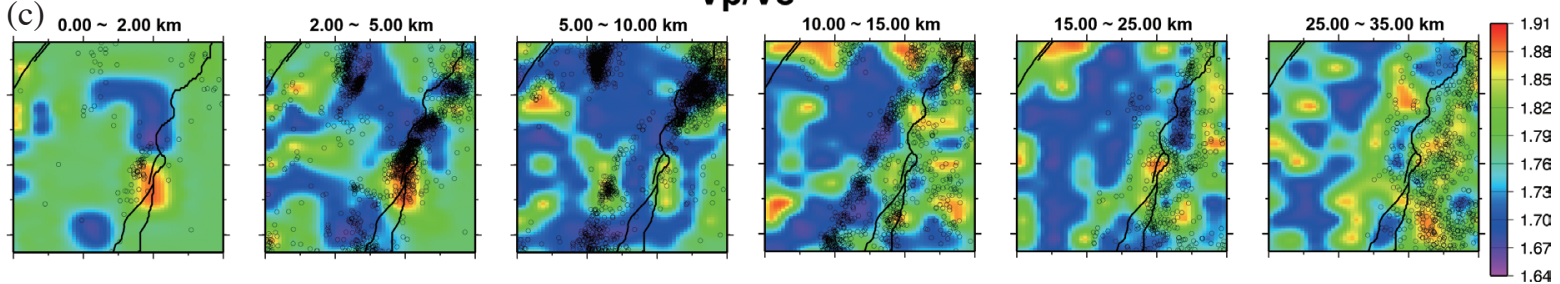

Fig. 3. Checkerboard test (top panel), derivative weighted sum (middle panel), and 3-D tomographic Vp/Vs structure (bottom panel) at six depth ranges $(0-2,2-5,5-10,10-15,15-25$, and $25-35 \mathrm{~km})$.

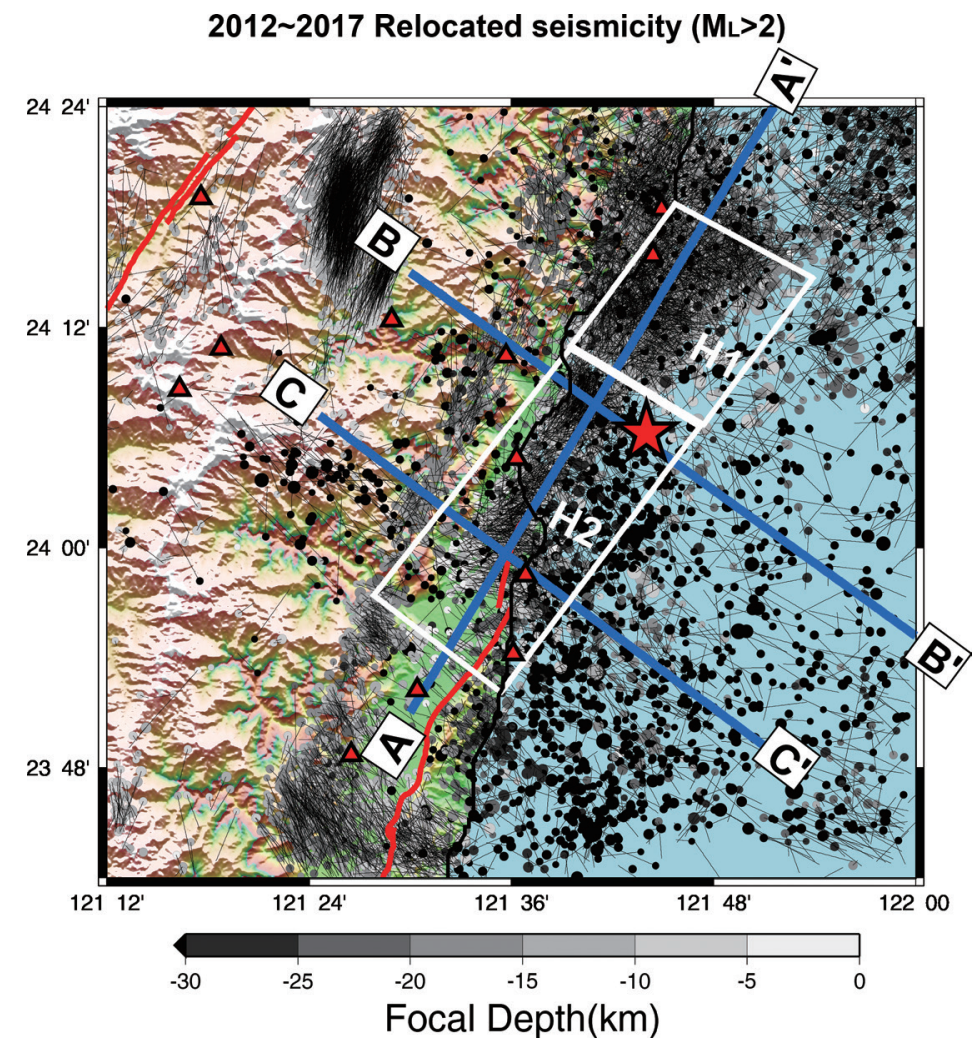

Fig. 4. Spatial distribution of relocated epicenters; the open circles indicate the relocated epicenters, whereas the end of each thin line represents the epicenters before relocation. Three lines represent the profiles AA', BB', and CC' and the two zones (white solid line, H1 and H2 zones) selected in this study. 
(Fig. 4). These relocated earthquakes yielded a significantly lower total travel-time misfit with an average RMS residual of $0.236 \mathrm{~s}$ (the original RMS residual is $0.607 \mathrm{~s}$ ). The average horizontal shifts of their epicenters was $3.53 \mathrm{~km}$ and that of their focal depths was $2.37 \mathrm{~km}$. However, the epicenters of relocated events that occurred in the oceanic region tended to shift toward land, which is reasonable as there is a lack of seismic stations in the ocean.

To understand the rupture behavior beneath the fault zones, we further used the recalculated azimuths and takeoff angles to obtain the focal mechanism before 2018 . Figure 5a shows the fault plane solutions in the study area; approximately 700 fault plane solutions were obtained, where the normal and strike-slip faulting types were distributed in the CMR. To improve the accuracy of the analysis, we calculated the take-off angles and azimuths from the obtained $3 \mathrm{D}$ tomography structure. With the polarities of P wave arrivals (Reasenberg and Oppenheimer 1985), we were able to obtain more than 700 focal mechanisms with magnitudes mostly between 3 and 5 . The results show several earthquake clusters in our study area. The distribution of relocated seismicity shows a distinct strip-shaped seismic zone near the CMR in the LV (see Fig. 4), with a predominantly reverse-faulting rupture mechanism. Furthermore, another obvious stripe-like seismic zone was observed near the $\mathrm{CR}$, where the predominant rupture mechanism is reverse faulting and strike-slip faulting. In particular, in the vicinity of the MLF and LDF, shallow and small earthquakes occur frequently as reported by the Central Weather $\mathrm{Bu}$ reau (https://www.cwb.gov.tw/V7/earthquake/rtd eq.htm). Along the fault to the oceanic side and close to off-shore of the Heping area (see the left upper inset in Fig. 1), another seismic cluster was observed, with thrust faulting as the dominant mechanism (see Fig. 5a). In the northwest of the study area, another group of shallow and small earthquakes with a predominant normal faulting rupture mechanism was observed (Fig. 5a).

For the 2018 Hualien earthquake source area, the relocated seismic events can be grouped into two zones (marked by $\mathrm{H} 1$ and $\mathrm{H} 2$ in Fig. 4) for further discussion. For a more systematic comparison, triangular charts that specify the distribution of focal mechanism (Figs. 5b and c) were analyzed (Frohlich 1992, 2001). The results show that a greater number of events had a thrust-like faulting regime than the strike-slip faulting. The triangular diagram for the $\mathrm{H} 1$ zone (Fig. 5b) shows that the seismic events were of the strikeslip $(\sim 30 \%)$ and thrust $(\sim 67 \%)$ rupture types. The $\mathrm{H} 2$ zone is the main location of the 2018 Hualien earthquake sequence, which the pattern for the $\mathrm{H} 2$ zone (see Fig. 5c, strike-slip type: $27 \%$; thrust type: $\sim 63 \%$ ) is also quite similar to that (a)

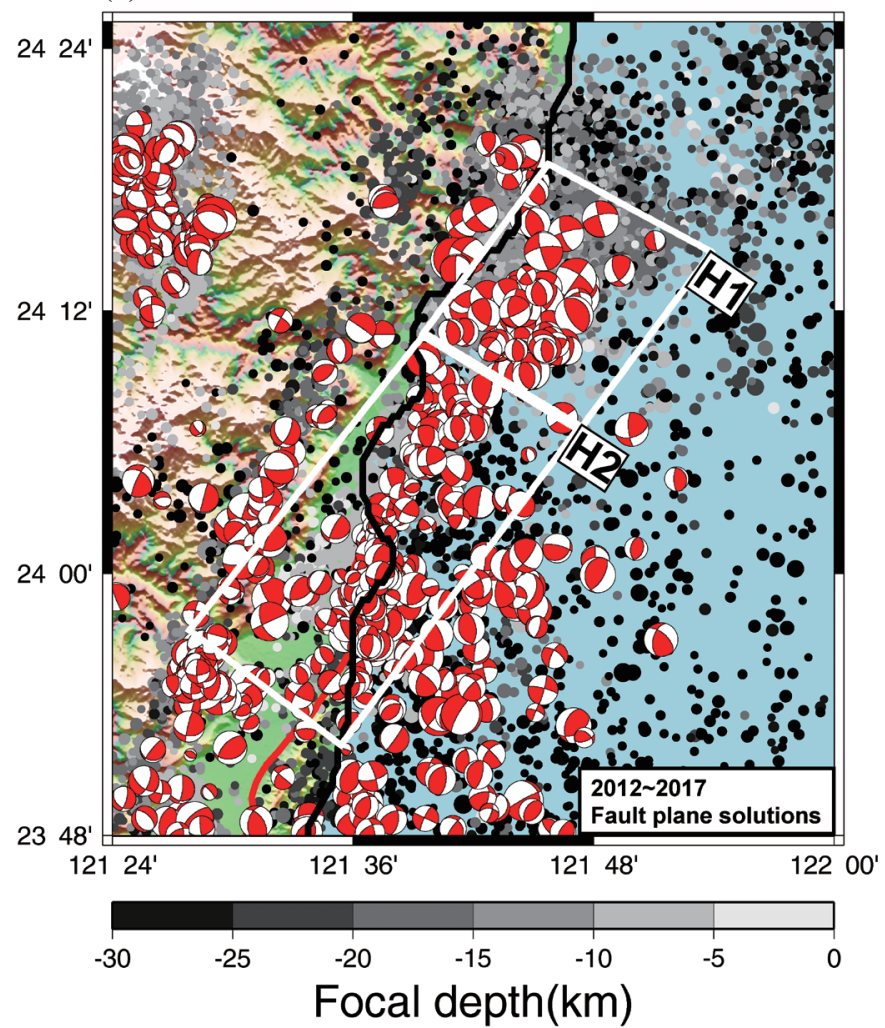

(b)

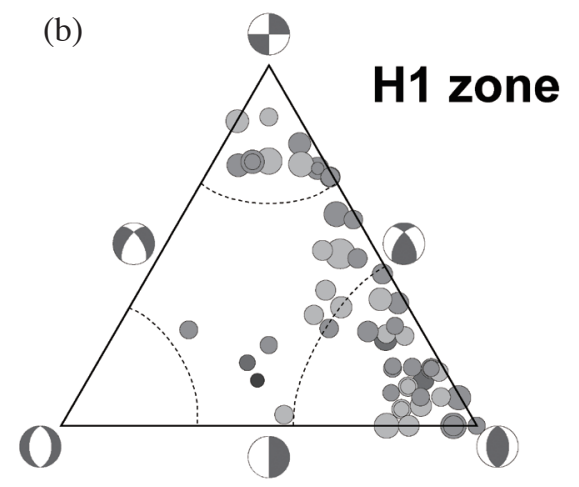

(c)

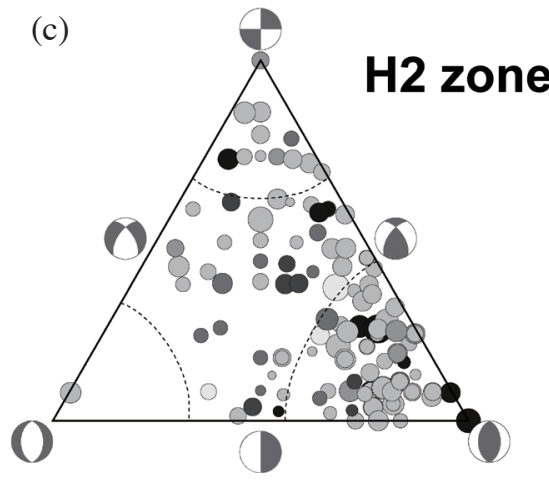

Fig. 5. (a) Distribution of focal mechanisms in the study area. (b) The triangular diagram for the H1 zone. (c) The triangular diagram for the H2 zone 
of the H1 zone. Therefore, the analysis of the past seismic data is still dominated by the thrust faulting pattern in the two zones, which is consistent with the previous studies (Wu et al. 2008; Hsu et al. 2010).

\section{RESULTS AND DISCUSSION}

This study aims to map the seismogenic structures before the 2018 Hualien earthquake. In this section, we will discuss the results in two parts. In the first part, we will discuss the results of deriving the velocity structures and $\mathrm{Vp} /$ Vs ratios. The epicenters were relocated and the velocity structures were derived through an iterative process. In the second part, we will discuss cross-sectional examination of the obtained velocity structures. In order to understand the velocity structures beneath the Hualien area, three cross sections were examined (Fig. 4). Two profiles almost perpendicular to the MLF, and one parallel to the MLF and LDF were observed. Thus, we will outline the relationships between the velocity structures, fault zones and seismicity.

As shown in Fig. 2, although numerous seismic events exist in each layer, most of them are located in a depth range of $2-25 \mathrm{~km}$. Therefore, in our inversion process, the seismic rays pass through most of the nodes. At depths of $0-5 \mathrm{~km}$, high and low $\mathrm{Vp}$ values show a belted distribution. In addition, low $\mathrm{Vp}$ anomalies are distributed in the vicinity of the fault zone (see Fig. 2c). At depths of $5-15 \mathrm{~km}$, the high $\mathrm{Vp}$ anomalies increase with depth and expand in a southeast. This may be related to the existence of oceanic crust structures beneath this area. Several cluster events existing in each layer and mostly show low Vp anomalies. In the vicinity of the fault zones, a high $\mathrm{Vp} / \mathrm{Vs}$ ratio anomaly is due to the increasing pore pressure, which leads to a decrease in the $\mathrm{S}$ wave velocity. We also observed that a low $\mathrm{Vp} / \mathrm{Vs}$ ratio anomaly broadens from north to south between 2 and $15 \mathrm{~km}$ and that the low anomaly zone extends to the CR with increasing depth (see Figs. 2c and 3c). This phenomenon can be attributed to the older and denser rock formations beneath the $\mathrm{CR}$, containing less fluid or $\mathrm{SiO}_{2}$, which will in turn result in lower $\mathrm{Vp} / \mathrm{Vs}$ ratios. Our results indicate that most seismic events are located in areas that have high or greatly varying $\mathrm{Vp} / \mathrm{Vs}$ ratios.

Figure 6a shows high and low anomaly zones in the $\mathrm{Vp}$, Vs and $\mathrm{Vp} / \mathrm{Vs}$ profiles in profile $\mathrm{AA}^{\prime}$. It can be observed that the velocity structures at the northern end of the $\mathrm{LV}$ are inclined to the north. In addition, a high $\mathrm{Vp}$ and $\mathrm{Vs}$
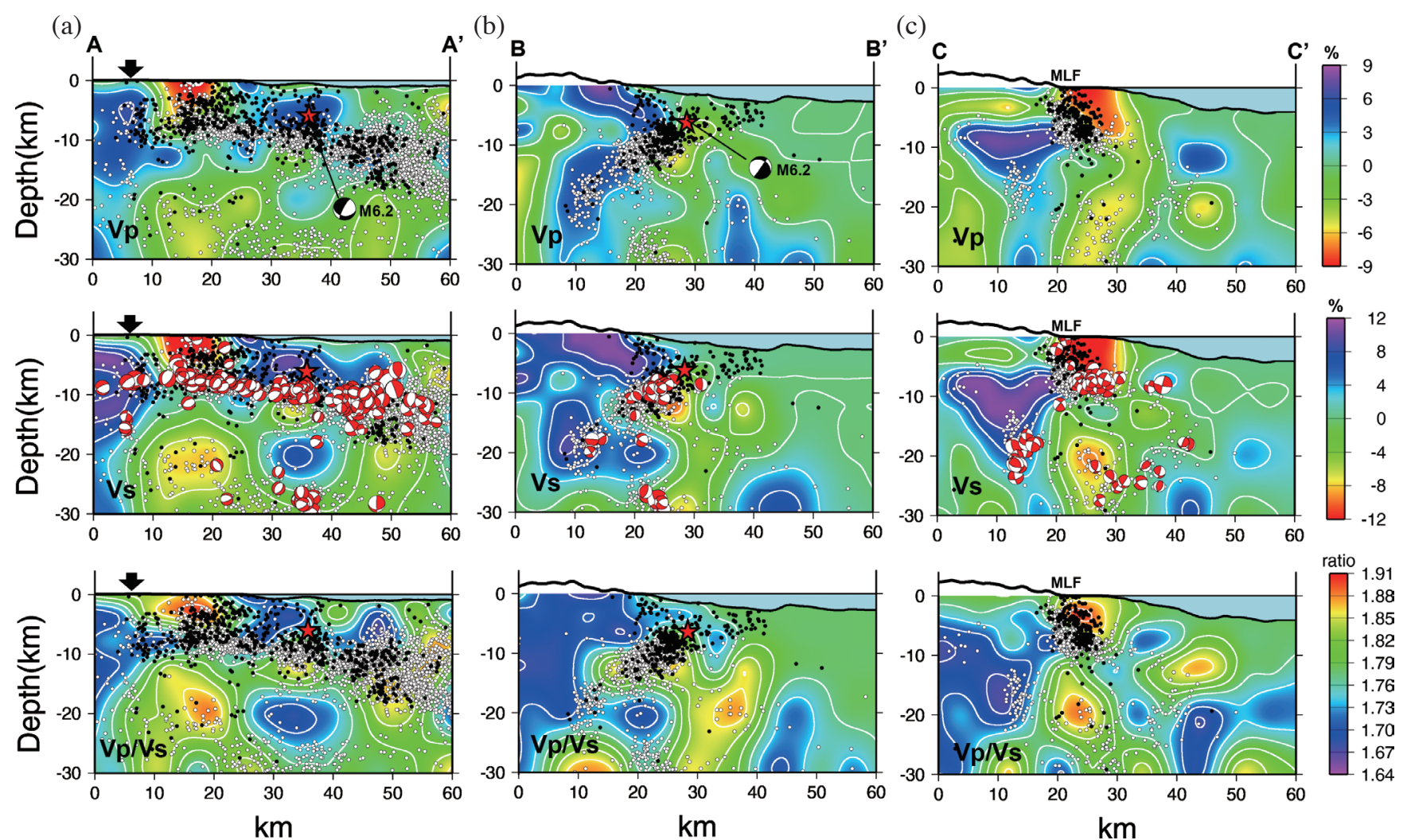

Fig. 6. (a) Tomographic $\mathrm{Vp}$, Vs, and Vp/Vs ratio structures along profile AA'. Circles represent seismic events used in the inversion for this profile (2012-2017, $\mathrm{M}_{\mathrm{L}}>2$ ), and the black dots are the seismic events that occurred in February 2018. The black arrow indicates the south-most boundary of the 2018 Hualien earthquake sequence. The fault plane solutions are illustrated in the Vs panel. (b) Same as in (a), but for profile BB'. (c) Same as in (a), but for profile CC'; MLF denotes the location of the Milun fault.

Note: The Vp and Vs values are shown by percentages of the differences with the values in the 1-D model. 
anomaly zone can be observed at the southern end of the AA' profile. The aftershock sequence of the Hualien earthquake (the preliminary locations which are indicated as the black dots in Fig. 6a) stops rupturing at the black arrow indicated in Fig. 6a. This feature needs further investigation in our future work. Figures $6 \mathrm{~b}$ and $\mathrm{c}$ show the anomalies in the $\mathrm{Vp}$, Vs and $\mathrm{Vp} / \mathrm{Vs}$ profiles in profile BB' and CC'. They indicate an eastward leaning fault geometry beneath the LVF zone at a depth of $5 \mathrm{~km}$, which implies that the fault may be an extension of the MLF; this can be considered as a passive rupture plane from the 2018 Hualien earthquake source inversion (Lee et al. 2018; Wen et al. 2019). In particular, in profile CC' (Fig. 6c), a low-velocity anomaly zone is observed in the shallow layer below the Milun Platform, where the earthquake cluster tends eastward. On the west side of the fault and at depths greater than $5 \mathrm{~km}$, a high $\mathrm{Vp}$ with high $\mathrm{Vp} / \mathrm{Vs}$ ratio anomaly area is observed, where an earthquake cluster tends to dip toward the west. The westdipping seismic zone may belong to the CRF and exhibits anomalous seismic activity, possibly owing to the high pore pressure, which can reduce the pressure to rupture (OugierSimonin and Zhu 2015). The abovementioned features were also observed from the velocity images of the eastern subduction zone obtained from Huang et al. (2014). Their results indicate an east-dipping seismic zone is in the northern part of the LV, and at depth greater than $10 \mathrm{~km}$, there also exists a seismic zone inclined toward to west [see Huang et al. (2014), profile DD' in Fig. 5]. In addition, both seismic zones are located at the boundary between high- and lowvelocity anomaly. Therefore, this anomaly area can be interpreted as an oversaturated pore pressure zone. These results also imply that the rupture behavior may be caused by the occurrence of localized supra-lithostatic fluid pressure on the steeply inclined thrust fault due to the inefficiency of hydro-fracturing (i.e., low friction coefficient) (Carminati et al. 2004).

We conclude that high seismicity exists in zones that exhibit a low $\mathrm{P}$ wave velocity and where the gradients of the $\mathrm{Vp} / \mathrm{Vs}$ ratio vary greatly in each profile. From profiles BB' and CC' (Figs. 6b and c), a west dipping seismic zone is clearly observed. The geometry of the seismic anomaly zone can also be identified as the main rupture plane of the 2018 Hualien earthquake as considered in the finite-fault model (Lee et al. 2018; Wen et al. 2019). A low rupture velocity across the Milun fault (e.g., Lee et al. 2018; Hwang et al. 2019) is possibly related to low velocity structures in the Milun Tableland (Fig. 6). Such low-velocity structures on land might be a factor contributing to the generation of pulse-like velocity waveforms at strong-motion stations located at the southernmost tip of the Milun fault (Kuo et al. 2019; Wu et al. 2019). In addition, low-velocity structures down to a depth of $10 \mathrm{~km}$ could restrain the rupture energy from growing into deeper regions. The teleseismic P-wave back-projection proposed by Jian et al. (2019) suggested that the rupture energy of the Hualien earthquake occurred above a depth of $10 \mathrm{~km}$. Nakajima et al. (2001) and Takei (2002) concluded that the variations in $\mathrm{Vp} / \mathrm{Vs}$ ratios may be due to water- or gas-filled cracks with high aspect ratios. They derived a coefficient, $d \ln V s / d \ln V p$, which represents a fractional change in $\mathrm{Vp}$ and $\mathrm{Vs}$ and can be used to determine whether the variation in $\mathrm{Vp} / \mathrm{Vs}$ ratios is caused by gas, water, or magma at a specific area (Takei 2002). Figure 7 shows that $\mathrm{dln} V \mathrm{~s} / \mathrm{dlnVp}$ is higher than 2 in the region with high seismicity and the anomaly areas, which indicates the presence of water-filled or high-density cracks. Therefore, results obtained from the tomography inversion at shallower fault segments show low Vs and high $\mathrm{Vp} / \mathrm{Vs}$ anomalies, which may imply that those zones are filled with fluid at crack openings (Figs. 6 and 7). This phenomenon is clearly observed in the fault zone in the northern part of the LV.
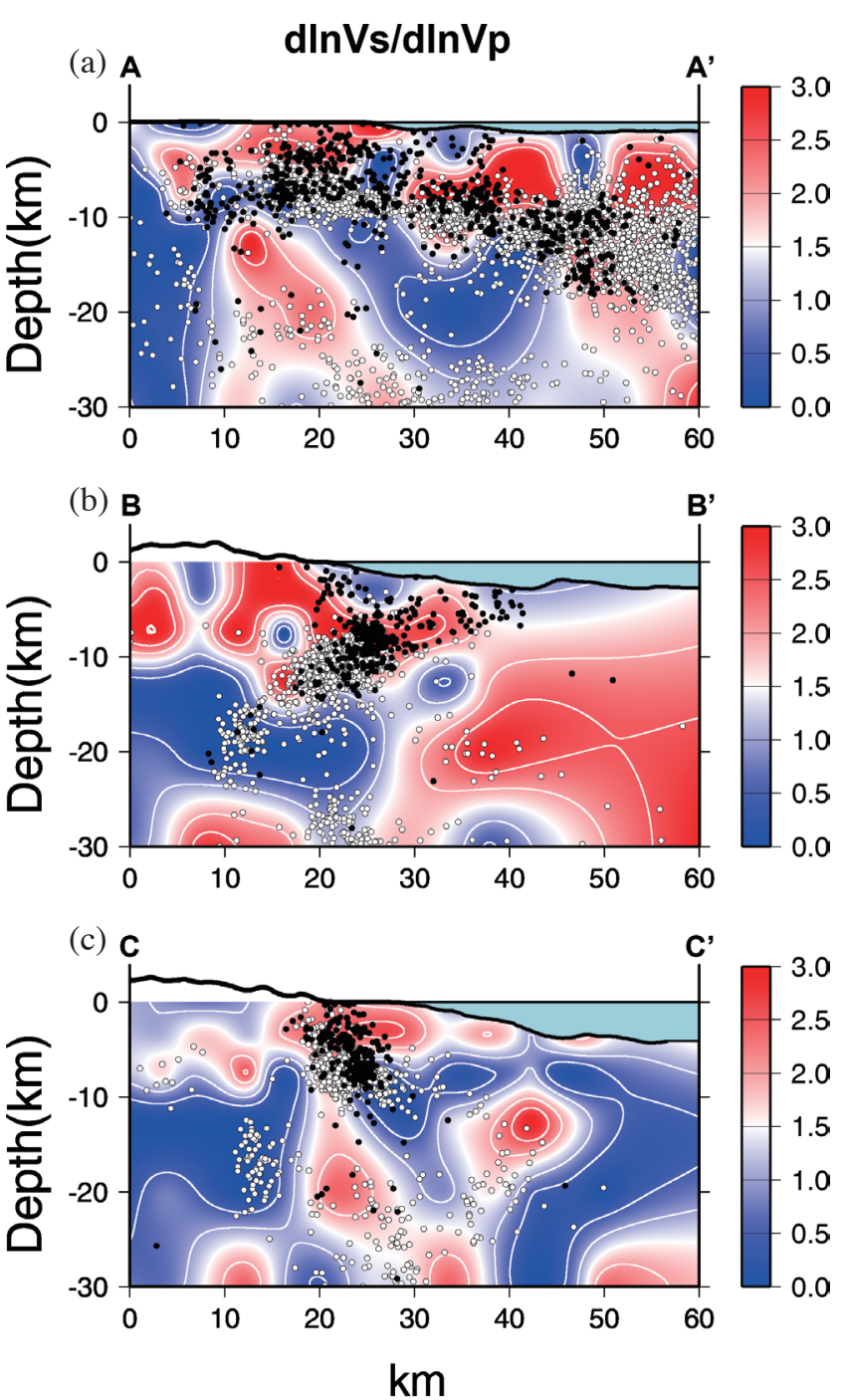

Fig. 7. (a) Distribution of the coefficient, $d \ln V s / d \ln V p$, along profile AA'. Circles represent seismic events used in the inversion for this profile (2012 - 2017, $\mathrm{M}_{\mathrm{L}}>2$ ). (b) and (c) are the same as in (a), but for profiles $\mathrm{BB}^{\prime}$ and $\mathrm{CC}^{\prime}$, respectively. 


\section{CONCLUSIONS}

In this study, we applied a damped least-square inversion method to investigate the $3 \mathrm{D} \mathrm{Vp}$ structures and $\mathrm{Vp} /$ Vs ratios of the crust and upper mantle beneath the Hualien area, eastern Taiwan, by using the travel-time data of seismic waves. By using the time difference between the observed $\mathrm{P}$ and $\mathrm{S}$ waves, we inverted the $\mathrm{Vp} / \mathrm{Vs}$ ratios. From the results, we could not only relocate earthquakes but also deduce the relationship between seismicity and the regional geological structures. In addition, we found that most earthquakes occurred in areas where the $\mathrm{Vp} / \mathrm{Vs}$ ratio gradients varied greatly. We also suggested that, instead of breaking the MLF, the mainshock of the 2018 Hualien earthquake may be associated with a west-dipping fault that could reach out to the Heping basin. Moreover, we concluded that the 2018 Hualien earthquake sequence occurred along a westdipping fault which is a blind fault and may belong to the CRF. The 3D velocity model derived from this study will help improve the accuracy of earthquake location and is an important factor in estimating strong ground motion. Therefore, the results obtained for the Hualien area using this model are of great significance in the prevention and mitigation of earthquake hazards.

Acknowledgements We thank the Geophysical Database Management System (http://gdms.cwb.gov.tw/index.php), developed by Central Weather Bureau (CWB) of Taiwan for providing seismic data. This research was supported by the Taiwan Earthquake Center (TEC) and funded through the Taiwan MOST grant MOST 106-2116-M-194-011 and MOST 107-2116-M-194-008.

\section{REFERENCES}

Carminati, E., C. Doglioni, and S. Barba, 2004: Reverse migration of seismicity on thrusts and normal faults. Earth-Sci. Rev., 65, 195-222, doi: 10.1016/S00128252(03)00083-7. [Link]

Chen, C. H., W. H. Wang, and Y. H. Yen 1994: 3-D velocity structure in Taiwan: A tectonic implication of continent-arc collision (abstract). Eos, Trans., AGU, 75, 645 .

Cheng, W. B., C. Wang, C. T. Shyu, and T. C. Shin, 2002: Crustal structure of the convergent plate-boundary zone, eastern Taiwan, assessed by seismic tomography. In: Byne, T. B. and C. S. Liu, (Eds.), Geology and Geophysics of an Arc-Continent collision, Taiwan, Republic of China. Boulder, Colorado, Geol. Soc. of Am. Special Paper 358, 163-177.

Chuang, R. Y., K. M. Johnson, Y. T. Kuo, Y. M. Wu, C. H. Chang, and L. C. Kuo, 2014: Active back thrust in the eastern Taiwan suture revealed by the 2013 Rueisuei earthquake: Evidence for a doubly vergent orogenic wedge? Geophys. Res. Lett., 41, 3464-3470, doi:
10.1002/2014GL060097. [Link]

Eberhart-Phillips, D. and A. J. Michael, 1998: Seismotectonics of the Loma Prieta, California, region determined from three-dimensional $V_{p}, V_{p} / V_{s}$, and seismicity. J. Geophys. Res., 103, 21099-21120, doi: 10.1029/98JB01984. [Link]

Frohlich, C., 1992: Triangle diagrams: Ternary graphs to display similarity and diversity of earthquake focal mechanisms. Phys. Earth Planet. Inter., 75, 193-198, doi: 10.1016/0031-9201(92)90130-n. [Link]

Frohlich, C., 2001: Display and quantitative assessment of distributions of earthquake focal mechanisms. Geophys. J. Int., 144, 300-308, doi: 10.1046/j.1365246x.2001.00341.x. [Link]

Hsu, Y.-J., L. Rivera, Y.-M. Wu, C.-H. Chang, and H. Kanamori, 2010: Spatial heterogeneity of tectonic stress and friction in the crust: New evidence from earthquake focal mechanisms in Taiwan. Geophys. J. Int., 182, 329-342, doi: 10.1111/j.1365246X.2010.04609.x. [Link]

Huang, H.-H., Y.-M. Wu, X. Song, C.-H. Chang, S.-J. Lee, T.-M. Chang, and H.-H. Hsieh, 2014: Joint Vp and Vs tomography of Taiwan: Implications for subductioncollision orogeny. Earth Planet. Sci. Lett., 392, 177191, doi: 10.1016/j.eps1.2014.02.026. [Link]

Hwang, R.-D., C.-Y. Lin, C.-Y. Lin, W.-Y. Chang, T.-W. Lin, Y.-L. Huang, and J.-P. Chang, 2019: Multipleevent analysis of the $2018 \mathrm{M}_{\mathrm{L}} 6.2$ Hualien earthquake using source time functions. Terr. Atmos. Ocean. Sci., 30, 367-376, doi: 10.3319/TAO.2018.11.15.01. [Link]

Jian, P. R., S. H. Hung, and L. Meng, 2019: Rupture behavior and interaction of the 2018 Hualien earthquake sequence and its tectonic implication. Seismol.Res. Lett., 90, 68-77, doi: 10.1785/0220180241. [Link]

Kao, H. and R. J. Rau, 1999: Detailed structures of the subducted Philippine Sea Plate beneath northeast Taiwan: A new type of double seismic zone. J. Geophys. Res., 104, 1015-1033, doi: 10.1029/1998jb900010. [Link]

Kim, K.-H., J.-M. Chiu, J. Pujol, K.-C. Chen, B.-S. Huang, Y.-H. Yeh, and P. Shen, 2005: Three-dimensional $V_{P}$ and $V_{S}$ structural models associated with the active subduction and collision tectonics in the Taiwan region. Geophys. J. Int., 162, 204-220, doi: 10.1111/j.1365246X.2005.02657.x. [Link]

Kissling, E., W. L. Ellsworth, D. Eberhart-Phillips, and U. Kradolfer, 1994: Initial reference models in local earthquake tomography. J. Geophys. Res., 99, 1963519646, doi: 10.1029/93jb03138. [Link]

Kuo, C. H., J. Y. Huang, C. M. Lin, T. Y. Hsu, S. H. Chao, and K. L. Wen, 2019: Strong ground motion and pulselike velocity observations in the near-fault region of the $2018 \mathrm{Mw} 6.4$ Hualien, Taiwan, earthquake. Seismol. Res. Lett., 90, 40-50, doi: 10.1785/0220180195. [Link] 
Kuo-Chen, H., Y. M. Wu, C. H. Chang, J. C. Hu, and W. S. Chen, 2004: Relocation of Eastern Taiwan Earthquakes and Tectonic Implications. Terr. Atmos. Ocean. Sci., 15, 647-666, doi: 10.3319/TAO.2004.15.4.647(T). [Link]

Kuo-Chen, H., F. T. Wu, and S. W. Roecker, 2012: Threedimensional $\mathrm{P}$ velocity structures of the lithosphere beneath Taiwan from the analysis of TAIGER and related seismic data sets. J. Geophys. Res., 117, B06306, doi: 10.1029/2011JB009108. [Link]

Lee, S. J., T. C. Lin, T. Y. Liu, and T. P. Wong, 2018: Faultto-Fault Jumping Rupture of the $2018 M_{\mathrm{w}} 6.4$ Hualien Earthquake in Eastern Taiwan. Seismol. Res. Lett., 90, 30-39, doi: 10.1785/0220180182. [Link]

Liaw, T. L. and Y. H. Yeh, 1983: Crustal structure of P wave velocity in northeastern Taiwan. Bull. Inst. Earth Sci., Acad. Sin., 3, 55-70.

Lin, C. W., W. S. Chen, Y. C. Liu, and P. T. Chen, 2009: Active faults of eastern and southern Taiwan. Central Geological Survey Special Publication, Vol. 23, MOEA, Taiwan.

Nakajima, J., T. Matsuzawa, A. Hasegawa, and D. Zhao, 2001: Three-dimensional structure of $V_{p}, V_{s}$, and $V_{p} /$ $V_{s}$ beneath northeastern Japan: Implications for arc magmatism and fluids. J. Geophys. Res., 106, 2184321857, doi: 10.1029/2000JB000008. [Link]

Ougier-Simonin, A. and W. Zhu, 2015: Effect of pore pressure buildup on slowness of rupture propagation. J. Geophys. Res., 120, 7966-7985, doi: 10.1002/2015JB012047. [Link]

Reasenberg, P. and D. H. Oppenheimer, 1985: FPFIT, FPPLOT and FPPAGE: Fortran computer programs for calculating and displaying earthquake fault-plane solutions. Open-File Report 85-739, U.S. Geological Survey, 109 pp, doi: 10.3133/ofr85739. [Link]

Shyu, J. B. H., K. Sieh, J. P. Avouac, W. S. Chen, and Y. G. Chen, 2006a: Millennial slip rate of the Longitudinal Valley fault from river terraces: Implications for convergence across the active suture of eastern Taiwan. J. Geophys. Res., 111, B08403, doi: 10.1029/2005JB003971. [Link]

Shyu, J. B. H., K. Sieh, Y. G. Chen, and L. H. Chung, 2006b: Geomorphic analysis of the Central Range fault, the second major active structure of the Longitudinal Valley suture, eastern Taiwan. Geol. Soc. Am. Bull., 118, 1447-1462, doi: 10.1130/B25905.1. [Link]

Shyu, J. B. H., L. H. Chung, Y. G. Chen, J. C. Lee, and K. Sieh, 2007: Re-evaluation of the surface ruptures of the November 1951 earthquake series in eastern Taiwan, and its neotectonic implications. J. Asian Earth
Sci., 31, 317-331, doi: 10.1016/j.jseaes.2006.07.018. [Link]

Takei, Y., 2002: Effect of pore geometry on Vp/Vs: From equilibrium geometry to crack. J. Geophys. Res., 107, doi: 10.1029/2001JB000522. [Link]

Thomas, M. Y., J. P. Avouac, J. Champenois, J. C. Lee, and L. C. Kuo, 2014: Spatiotemporal evolution of seismic and aseismic slip on the Longitudinal Valley Fault, Taiwan. J. Geophys. Res., 119, 5114-5139, doi: 10.1002/2013JB010603. [Link]

Thurber, C. H., 1983: Earthquake locations and three-dimensional crustal structure in the Coyote Lake Area, central California. J. Geophys. Res., 88, 8226-8236, doi: 10.1029/JB088iB10p08226. [Link]

Toomey, D. R. and G. R. Foulger, 1989: Tomographic inversion of local earthquake data from the Hengill-Grensdalur Central Volcano Complex, Iceland. J. Geophys. Res.,94, 17497-17510, doi: 10.1029/jb094ib12p17497. [Link]

Wen Y.-Y., Y.-T. Yen, S. Wen, S.-J. Lee, C.-H. Kuo, and Y.-Y. Lin, 2016: Hybrid ground motion simulation for the $2013 \mathrm{M}_{\mathrm{L}}$ 6.4 Ruisui, Taiwan earthquake. Terr. Atmos. Ocean. Sci., 27, 407-414, doi: 10.3319/ TAO.2015.10.30.01(TEM). [Link]

Wen, Y.-Y., S. Wen, Y.-H. Lee, and K.-E. Ching, 2019: The kinematic source analysis for $2018 \mathrm{M}_{\mathrm{w}} 6.4$ Hualien, Taiwan earthquake. Terr. Atmos. Ocean. Sci., 30, 377-387, doi: 10.3319/TAO.2018.11.15.03. [Link]

Wu, Y. M., C. H. Chang, L. Zhao, J. B. H. Shyu, Y. G. Chen, K. Sieh, and J. P. Avouac, 2007: Seismic tomography of Taiwan: Improved constraints from a dense network of strong motion stations. J. Geophys. Res., 112, doi: 10.1029/2007JB004983. [Link]

Wu, Y. M., L. Zhao, C. H. Chang, and Y. J. Hsu, 2008: Focal-mechanism determination in Taiwan by genetic algorithm. Bull. Seismol. Soc. Am., 98, 651-661, doi: 10.1785/0120070115. [Link]

Wu, Y. M., H. Mittal, T. Huang, B. M. Yang, J. Jan, and S. K. Chen, 2019: Performance of a low-cost earthquake early warning system (P-Alert) and shake map production during the $2018 \mathrm{Mw} 6.4$ Hualien, Taiwan, earthquake. Seismol. Res. Lett., 90, 19-29, doi: 10.1785/0220180170. [Link]

Yeh, Y. H., C. H. Lin, and S. W. Roecker, 1989: A study of upper crustal structures beneath northeastern Taiwan: Possible evidence of the western extension of Okinawa trough. Proc. Geol. Soc. China, 32, 139-156.

Yu, S. B., H. Y. Chen, and L. C. Kuo, 1997: Velocity field of GPS stations in the Taiwan area. Tectonophysics, 274, 41-59, doi: 10.1016/s0040-1951(96)00297-1. [Link] 